\title{
Profile of Death Due to Thermal Burns: A Retrospective Study
}

\author{
Shailendra Patel ${ }^{1}$, Jitendra Singh Tomar², Ankit Pandey Jain ${ }^{3}$, Poornima Patel ${ }^{4}$ \\ ${ }^{1}$ Assistant Professor, Department of Forensic Medicine and Toxicology, Bundelkhand Medical College, Sagar \\ (M.P), ${ }^{2}$ Assistant Professor, Department of Forensic Medicine and Toxicology, MGM Medical College, Indore \\ (M.P), ${ }^{3} P G$ resident, Department of Forensic Medicine and Toxicology, MGM Medical College, Indore (M.P), \\ ${ }^{4}$ Dental Surgeon at Aashirwad Dental Clinic, Sagar
}

\begin{abstract}
Fire is one of the important element of life, it is both useful (in cooking, producing warmth in winter, in cremation etc.) as well as harmful (by producing thermal burn injuries, blast injuries, forest fire, crop burning, volcanic eruption etc.) to the mankind. Burn injury is now becoming the major cause of death among unnatural deaths in various regions of the country and world. Majority of the burn cases occurat home due to smoking, defective electrical wiring, defective kerosene stove bursts, attempted suicides by self-immolation, homicidal burns of young women by husband or in-laws (dowry deaths). The present study was based on retrospective analysis of post mortem cases of thermal burns during the period from January 2018 to December 2018 in the Department of Forensic Medicine and Toxicology, Bundelkhand Medical College, Sagar (M.P). During this period total 349 autopsies were conducted, out of which majorities of death, 116 cases were due to burn. Majority of the victims were married hindu females belonging to age group of 21-30 years. Of these cases carbon soot particles in trachea were present in $7 \%$ of cases and kerosene smell was present in $21 \%$ cases. Most of deaths were accidental account for $78.44 \%$ cases. Police inquest was conducted in $76 \%$ of the cases and rest of the cases were magistrate inquest. In 52(44.82\%) cases, $60-80 \%$ of Total Body Surface Area (TSBA) was burnt of all body parts upper extremities were commonly involved in about $96.55 \%$ cases. Accidental burn injuries are preventable and can be reduced by bringing about regulations to develop safer cooking appliances, promoting less inflammable fabrics to be worn at home and educating the community especially women.
\end{abstract}

Keywords: Thermal burns, Married female, Soot particles, Kerosene smell.

\section{Introduction}

Burns are the injuries that are produced by the application of dry heat such as flame, radiant heat and some heated solid substance like metal or glass to the surface of the body resulting in tissue destruction. In young adult population, about $40 \%$ burn is fatal. ${ }^{1}$

There are varieties of types of lethal and nonlethal thermal injury, including flame burns which char skin and singe hair, scalding from hot fluids and contact burns those result from touching hot objects. An estimated 180000 deaths every year are caused by burns and among those, vast majority occur in low and middleincome countries. In India, every year 1000000 people are moderately or severely injured due to burn injury. ${ }^{2}$ Burn injuries are the $4^{\text {th }}$ most common type of trauma all over the world, following traffic accidents, falls and interpersonal violence. $^{3}$

The accidental burn injury is the commonest manner of burns. ${ }^{4}$ Accidental burn are commonly seen in females as most of the females (housewives) spend most of their time in household work especially in kitchen. Burn is also important mode of suicide and homicide in the world. Setting of fire to self (self-immolation) in public is done to attract the attention of government and media regarding political affairs, personal problems. Sometimes people resort to criminal acts like murder, rape and for concealing the facts, they try to burn the body of crime.

Dowry death is still a subject of major concern in our recent modern society in spite of strict law and amendment in the acts..$^{5}$ Almost every day we read in newspapers and see in electronic media,cases of young 
women either being burnt or provoked to commit suicide by the husband and in-laws, just for the dowry. ${ }^{6}$

\section{Materials and Methodology}

The present study is a retrospective study carried out in the Department of Forensic Medicine \& Toxicology, Bundelkhand Medical College, Sagar (M.P). A total of 349 autopsies were performed during the period of Jan 2018 to Dec 2018, out of which 116 thermal burn deaths were analysed. The detailed analysis of these cases was based on the inquest record, hospital records and evaluation of autopsy reports. Various parameters like age, sex, religion, carbon soot particles in trachea, presence of kerosene smell, type of inquest, manner of death, marital status, body parts burnt and TBSA burnt were taken into consideration. The information was compiled, tabulated and analysed.

\section{Results}

During the period of one year from $1^{\text {st }}$ Jan 2018 to $31^{\text {st }}$ Dec 2018, total 349 autopsies were conducted, out of which $116(33.2 \%)$ cases were due to burn. Out of total cases of burn, 22(19\%) were male and $94(81 \%)$ were female and male: female ratio was 1:4.2. (Graph 1).

Taking age group into consideration, maximum incidence of burn injuries in males were noted in the age group of 21-30 years i.e. $8(6.89 \%)$ whereas in the age group of above 50 years no case was reported. The maximum incidence in females was noted in the age group of 21-30 years i.e. $48(41.37 \%)$ and minimum in the age group of 1-10 years i.e.3 (2.58\%) cases. Taking overall population into consideration, Maximum incidence of burn injuries were noted in the age group of 21-30 years i.e. $56(48.27 \%)$ and minimum in the age group of above 50 years i.e. 4 (3.44). (Table 1).
Looking into the marital status among the burn cases, married cases were higher 96 cases $(82.75 \%)$ as compared to unmarried cases 20 cases (17.24\%). Out of total married cases, $80(83.3 \%)$ victims were female while the rest $16(16.6 \%)$ were male. Most of the victims belong to the Hindu community comprising $110(94.82 \%)$ and the rest 06 (5.17\%) were from Muslim community. Female victim predominance were seen in both Hindus (90 cases out of 110) and Muslims (4 cases out of 6).

Out of all burn cases,deposition of carbon soot particles in trachea was observed in 08 (7\%) cases. (Graph 2) Kerosene smell was present in 24 (21\%) cases, absent in 92 (79\%) cases.

Out of total 116 burn cases, magistrate inquest was carried out in $28(24 \%)$ cases and police inquest in $88(76 \%)$ cases. In most of the burn victims the manner of death was accidental in 91 cases (78.4\%) followed by suicidal in 18 cases $(15.5 \%)$ and 07 cases $(6 \%)$ shows homicidal pattern. (Graph 3)

Distribution of burn cases according to involvement of Total Body Surface Area (TBSA), shows that in majority of burn cases (52.6\% cases) TBSA was above $60 \%$, followed by $35.3 \%$ cases with $41-60 \%$ of TBSA. Only $12 \%$ cases died with TBSA less than $40 \%$. In $10.34 \%$ male cases, TBSA involved was $41-60 \%$ and in females, in $39.65 \%$ cases TBSA involved was $61-80 \%$.

(Table 2).

In burnt areas upper extremities were most commonly affected i.e. in $112(96.55 \%)$ cases, followed by head, neck and face in $105(90.51 \%)$ cases. Genitalia was the least affected and involved in $27(23.27 \%)$ cases. (Table 3).

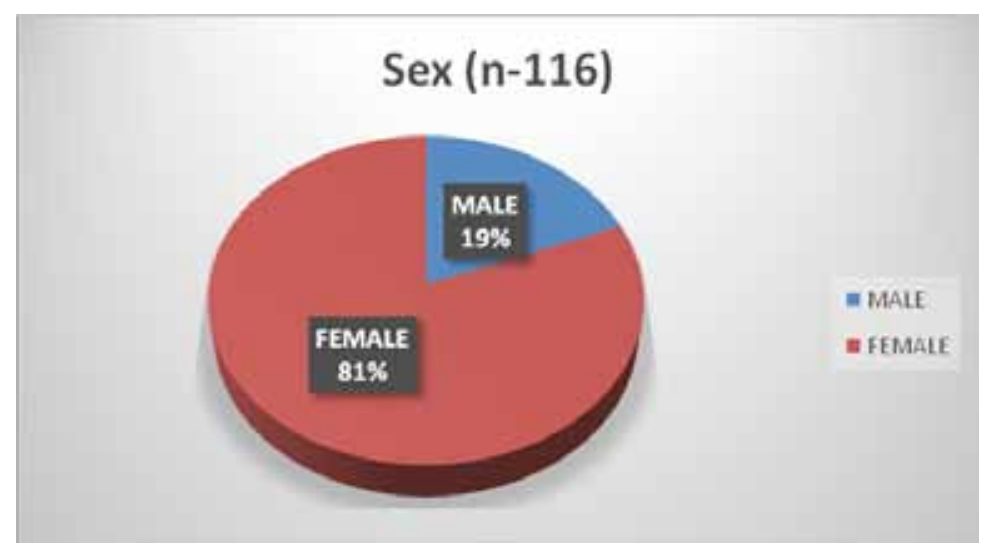

Graph 1: Sex Wise Distribution of Burn Cases 


\section{Soot Particle in Trachea \\ $(n-116)$}

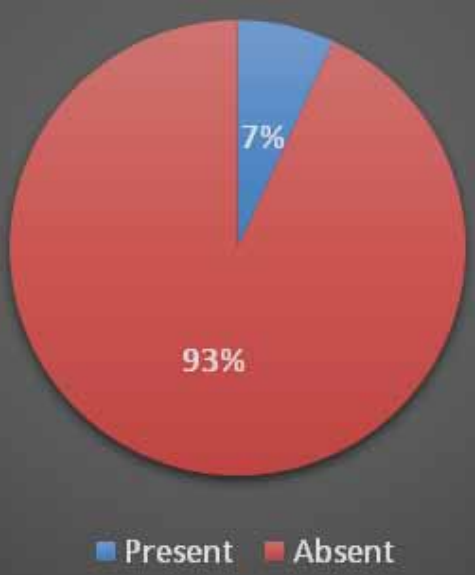

Graph 2: Soot Particles Present in Trachea

\section{Manner of Death(n-116)}

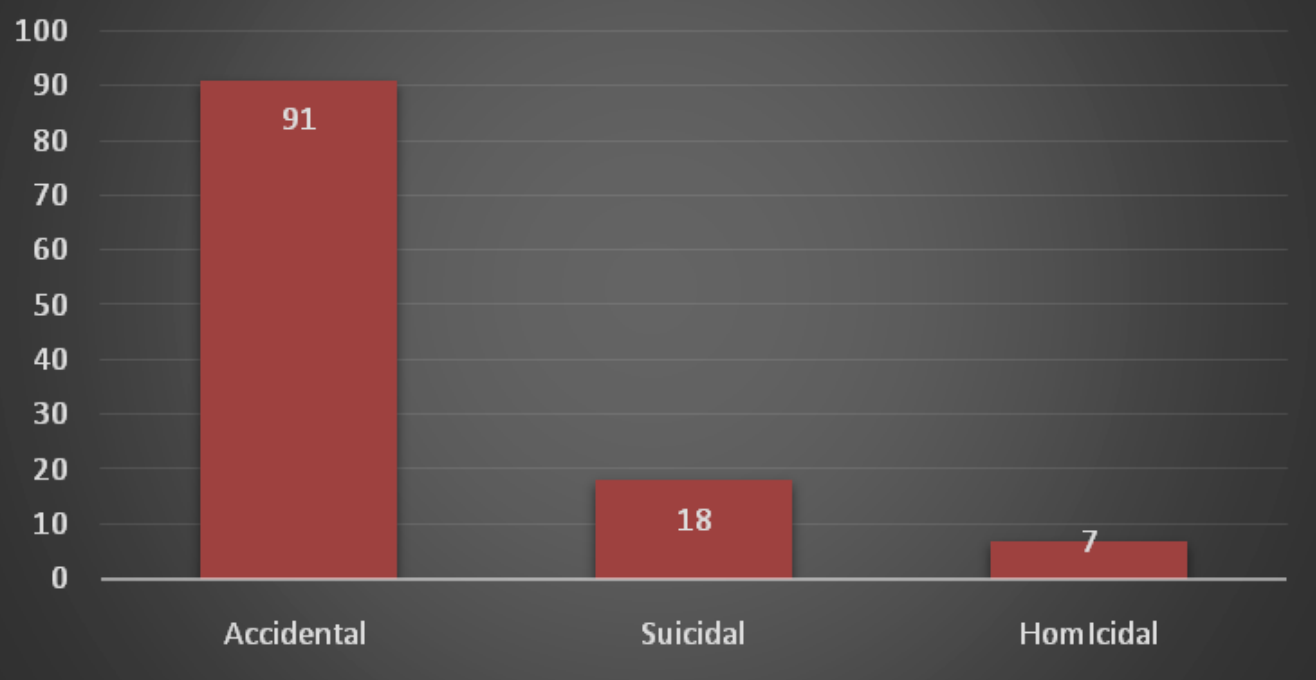

Graph 3: Distribution on the basis of Manner of Death

Table 1: Age wise Distribution of Burn Cases $(n=116)$

\begin{tabular}{|c|c|c|c|}
\hline Age & Male (\%) & Female (\%) & Total (\%) \\
\hline $0-10$ & $02(1.72)$ & $03(2.58)$ & $05(4.31)$ \\
\hline $11-20$ & $02(1.72)$ & $19(16.37)$ & $21(18.10)$ \\
\hline $21-30$ & $08(6.89)$ & $48(41.37)$ & $56(48.27)$ \\
\hline $31-40$ & $07(6.03)$ & $14(12.06)$ & $21(18.10)$ \\
\hline $41-50$ & $03(2.58)$ & $06(5.17)$ & $09(7.75)$ \\
\hline$>50$ & 00 & $04(3.44)$ & $04(3.44)$ \\
\hline Total & $\mathbf{2 2}(\mathbf{1 8 . 9 6})$ & $\mathbf{9 4}(\mathbf{8 1 . 0 3})$ & $\mathbf{1 1 6}(\mathbf{1 0 0})$ \\
\hline
\end{tabular}


Table 2: Distribution of burn cases according to involvement of Total body surface area (n=116)

\begin{tabular}{|c|c|c|c|}
\hline Total Body Surface Area Involved & Male (\%) & Female (\%) & Total (\%) \\
\hline$<40 \%$ & $04(3.44)$ & $10(8.6)$ & $14(12.06)$ \\
\hline $41-60 \%$ & $12(10.34)$ & $29(25.0)$ & $41(35.34)$ \\
\hline $61-80 \%$ & $06(5.17)$ & $46(39.65)$ & $52(44.82)$ \\
\hline$>80 \%$ & 0 & $09(7.75)$ & $09(7.75)$ \\
\hline Total & $\mathbf{2 2 ( 1 8 . 9 6 )}$ & $\mathbf{9 4}(\mathbf{8 1 . 0 3})$ & $\mathbf{1 1 6}(\mathbf{1 0 0})$ \\
\hline
\end{tabular}

Table No. 3: Distribution of burn injuries on the body $(n=116)$

\begin{tabular}{|l|c|c|}
\hline Area of body burnt & Total no. of cases & Percentage (\%) \\
\hline Head, neck and face & 105 & $90.51 \%$ \\
\hline Chest and abdomen & 101 & $87.06 \%$ \\
\hline Back & 84 & $72.41 \%$ \\
\hline Upper Extremities & 112 & $96.55 \%$ \\
\hline Lower Extremities & 95 & $81.89 \%$ \\
\hline Genitalia & 27 & $23.27 \%$ \\
\hline
\end{tabular}

\section{Discussion}

In the present study of deaths due to burn injuries, Female $(81 \%)$ dominates male $(19 \%)$ in the incidence on the basis of sex, which is similar with the finding of other similar studies. $5,6,7,8,9,10,11,12,13$ Females were more susceptible to burn injuries as they spend most of their time in kitchen and are involved in the activities which require fire like cooking food, making tea, boiling water etc. As we see in rural area most of the houses have no proper equipment for cooking and other fire related work, so in such area female are more prone for burn injuries. But in fewer studies slight male predominance was also observed. ${ }^{14,15}$ The reason for male predominance could be occupational hazard.

Age group of 21-30 years have maximum incidence of deaths due to burn in both males i.e. $8(6.89 \%)$ and females i.e. $48(41.37 \%)$. Similar findings were observed in other studies also. ${ }^{10,11,12,13,14,16,17}$ This age group of 21-30 years is the young adult group and is the most common age for marriage in this area of study.

In the present study, it was observed that 96 $(82.75 \%)$ victims were married and $20(17.24 \%)$ were unmarried. Out of the females $80(68.96 \%)$ were married and $14(12.06 \%)$ were unmarried in contrast to males 16 $(13.79 \%)$ were married and 06 (5.17\%) were unmarried. Similar finding was also noted in other studies. ${ }^{6,7,11,12,18}$
Majority of victims were married female,this might be because of their involvement in domestic cooking work and dowry deaths.

Most of the victims belonged to the Hindu community i.e. $110(94.82 \%)$ as compared to Muslims i.e. $06(5.17 \%)$. Among the Hindus, majority of victims were female i.e. $90(81.8 \%)$ as compared to males i.e. $20(15.2 \%)$.which is similar to the findings of previously mentioned studies..$^{8,9,10,11,19}$ This is because in this part of the world and more specifically in this region Hinduism is the most commonly followed religion, resulting in increased incidence among Hindus.

Out of total 116 burn cases, soot particles were found in trachea in $08(7.0 \%)$ cases, which is almost similar with the finding of Mishra PK et $\mathrm{al}^{11}$, who found soot particles in $5.55 \%$ cases. But different from the findings of Das $\mathrm{KC}$ et $\mathrm{al}^{8}$, who found soot particles in trachea in $18.05 \%$ cases, Nath $\mathrm{D}$ et $\mathrm{al}^{9}$, who found in $34.07 \%$ cases and Mazumdar A et $\mathrm{al}^{4}$, who found soot particles intrachea in $19 \%$ cases.

In the present study kerosene smell was found evident in $24(21 \%)$ cases. This finding in our study is near to the finding of Mishra PK et $\mathrm{al}^{20}$, who observed kerosene smell in $27.5 \%$ of cases. Whereas on the contrary Chaudhary BL et $\mathrm{al}^{21}$ in their study observed smell of kerosene in only $4 \%$ cases. This might be due 
to its easy availability and its extensive use in household purposes for cooking and in lighting lamps in the rural areas as there is less availability of cooking gas and electricity in rural areas. Many people use kerosene as a fuel for motor vehicles and it is also a major fuel foraircraft engine.

On the basis of manner of deaths, majority of deaths were accidental in nature i.e. in $78.44 \%$ cases followed by suicidal i.e. $15.51 \%$ cases. This may be due to involvement of females in domestic cooking. This was responsible for accidental cases and maritalmaladjustment resulting in suicidal cases. Homicidal deaths are less comparatively i.e. in $6.03 \%$ cases and commonly seen in case of dowry killing may be by husband or inlaws. In this study majority of deaths were accidental in nature, which is similar to other studies. $6,7,8,13,20$

In present study, majority of the victims i.e. 102 (88\%) had more than $40 \%$ of Total body surface area (TBSA) burn and there are fewer number victims i.e. 14 (12\%) below 40\% TBSA burn. In studies by Mishra PK et al $^{11}$ revealed $86.3 \%$ mortality over $40 \%$ TBSA, Similarly, in studies from Adamo $\mathrm{C}$ et $\mathrm{al}^{22}$ revealed $100 \%$ mortality over $40 \%$ TBSA and Gupta $\mathrm{M}$ et $\mathrm{al}^{23}$ also shows similar finding, $80 \%$ mortality rate in burn over $40 \%$ TBSA. Similar finding were also noticed in study by Mangal HM et al ${ }^{6}$ showing 92.8\% mortality over $40 \%$ TBSA burn and Tomar $\mathrm{J}$ et al ${ }^{5}$ shows $100 \%$ mortality over 50\% TBSA. All these studies signify that burn of 40-50 \% TBSA and above was fatal resulting in large number of deaths even at tertiary care centre.

In present study upper extremities were most commonly involved in $112(96.55 \%)$ cases, followed by head, neck and face in 105 (90.51\%) cases. Similar findings were observed in the study done by Tomar $\mathrm{J}$ et $\mathrm{al}^{5}$ with most of the cases involving upper limbs (93.5\%), followed by chest and abdomen (86.11\%), lower limbs (63.8\%) and genitalia (14.81\%).

In present study upper extremities were most commonly involved in $112(96.55 \%)$ cases, followed by head, neck and face in 105 (90.51\%) and Genitalia involved in only $23.27 \%$ cases. Similar findings were observed in the study done by Tomar $\mathrm{J}$ et $\mathrm{al}^{5}$ with most of the cases affecting upper limbs (97.5\%), followed by head, neck and face $(90.83 \%)$, chest \& abdomen $(88.33 \%)$ and least affecting part is genitalia $(20 \%)$. In contrast to the present study, Buchade $\mathrm{D}$ et $\mathrm{al}^{7}$ found that Head, face \& neck region was most commonly affected in 206 (86.91\%) cases, followed by chest in 174 (73.41\%) cases.

\section{Conclusion}

Our present study and other above discussed studies,shows that married females are commonly affected due to burns because they are commonly involved in domestic cooking work. Most of the burns are accidental and can be prevented by following the safety instructions like putting the lights off while going out, wearing tight and cotton cloths while cooking, not leaving a fire source unattended etc. The government should work in the direction to reduce the incidences of burn by bringing about regulations to develop safer cooking appliances and educating the community especially women on safer first aid practices. The government along with various working groups and the NGOs, including the doctors need to put in more sincere effort. Proper knowledge and training should be given to all the factory workers involve in fire work in order to prevent accidental burn among male and females both. The present study is concluded with the hope that the given suggestions will help in reducing the number of burn injuries.

\section{Conflict of Interest: Nil}

\section{Source of Funding: Self}

Ethical Clearance: It's a retrospective study and identity of the deceased is nowhere disclosed. Therefore, the approval of Institutional Ethics Committee is not required.

\section{References}

1. Dikshit PC. Textbook of forensic medicine and toxicology. $2^{\text {nd }}$ Edition. New Delhi PEEPEE Publishers 2014:253-256.

2. W.H.O. Burns, 2018. Available at: https://www. who.int/news-room/fact-sheets/detail/burns/ accessed on 28 April 2020.

3. Pekka S, Knight B. The pathology of burns. Bernard Knight's Forensic Pathology. 3rd ed. New York: Oxford University Press Inc; 2004: 322.

4. Van Rijn JL Olga, Bouter LM, Meertens RM. The aetiology of burns in developed countries: review of the literature. Burns. 1989;15(4):217-21.

5. Tomar J, Mishra PK, Sane MR, Saxena D, Varun A. Epidemiology and Outcome of Burn InjuriesA Prospective study. Indian Journal of Forensic 
Medicine and Community Medicine, 2019; 04(1):59-63.

6. Mangal HM, Pathak A, Rathod JS. The Fire is Both "A Blessing \& Scourge to the Mankind"JIAFM, 2007, 29(4) 75-77.

7. Buchade D, Kukde H, Dere R, Savardekar R. Pattern of Burn Cases Brought to Morgue, Sion Hospital Mumbai, A Two-Year Study. JIAFM 2011; 33(4): 309-310.

8. Das. K.C. A study of burn cases in medico-legal autopsy. MDthesis, 1998; Guwahati University, Guwahati, Assam, India.

9. Nath D. A statistical study of pattern of ante mortem burns injuries.MD thesis, 2007; Guwahati University, Guwahati, Assam, India.

10. Mazumder A, Patowary A. A Study of Pattern of Burn InjuryCases. JIAFM 2013; 35(1): 44-46.

11. Mishra PK, Tomar J, Sane MR, Saxena D, Yadav A. Profile of Death in Burn Cases: A Post-mortem Study. JIAFM 2016; 38(1): 8-10.

12. Harish D, Kaur C, Singh A, Kumar A. A Comprehensive Analysis of Deaths due to Burns in a Tertiary Care Centre. J Punjab Acad Forensic Med Toxicol, 2013, 13(2) 68-73

13. Prasad CS, Shubendu K, Gawasker SP, Singh NK. Profile of Burn Injuries among Autopsies Conducted in Dept. of Fmt, Rims, Ranchi: IOSRJDMS, 2017; Vol.16, no.08:53-57.

14. Memchoubi, H. Nabachandra. A Study of Burn Deaths in Imphal. J IAFM, 2007, 29(4) 131-134.

15. Dandpat MC, Sethi.Management of Burns. Indian Medical Gazette. 1984
16. Chawla R, Chanana A, Rai H, Aggarwal AD, Singh H, Sharma G. A Two-year Burns Fatality Study. J Indian Acad Forensic Med, 2010, 32(4) 292-297.

17. Ande JD, Kumar SV, Satyadev M, Tirumala N, Guguloth K, Chandana N. Pattern of Thermal Burn Injuries and their outcomes at Burn Care Unit of Tertiary Hospital, Warangal, Andhra Pradesh, India. International Journal of Pharmaceutical Sciences Letters 2013 Vol. 3 (6) 288-295.

18. Gaffar UB, Husain M, Rizvi SJ. Thermal Burn: An Epidemiological Prospective Study. J Indian Acad Forensic Med, 2008, 30(1) 10-14

19. Singh P, Harish D. Incidence of Post Burn Septicaemia in ATertiary Care Hospital, JIAFM. 2011; 33(4): 317-320.

20. Mishra PK, Tomar J, Saxena D, Verma P, Varun A. Medicolegal aspect of Thermal burns - A Prospective study, JIAFM 2016; 38(1): 8-10.

21. Chaudhary BL, Yadav P, Kumar M, Rahul B. Mortality Profile of Burn Injuries: A Postmortem Study in Lady Hardinge Medical College, New Delhi. J Indian Acad Forensic Med, 2013, 35(2) 123-126

22. Adamo C, Esposito G, Lissia M, Vonella M, Zagaria N, ScuderiN. Epidemiological data on burn injuries in Angola: a retrospectivestudy of 7230 patients. Burns 1995; 21:536-8.

23. Gupta M, Gupta OK, Yaduvanshi RK, Upadhyaya J. Burnepidemiology in Pink city scene. Burns 1993; 22:47-51 